Eskişehir Osmangazi Üniversitesi iißBF Dergisi

Ağustos 2019, C. 14, S. 2, $263-276$.

Başvuru : 23.05.2018

Kabul : :26.07.2019

\title{
Sosyolojik Bir Kategori Olarak Heterodoks Iiktisat
}

Hüsnü Bilir ${ }^{1}$

Sosyolojik Bir Kategori Olarak Heterodoks İktisat

Öz

Günümüzde heterodoks iktisat terimi Veblen, Marx, Robinson, Sraffa -hatta kimi zaman Keynes ve Hayek- gibi düşünürleri ve post-Keynesyen iktisat, Marksist iktisat, Sraffacı (neo-Ricardocu) iktisat, yapısalcı iktisat, kurumcu iktisat, sosyal iktisat ve evrimci iktisat gibi düşünce okullarını ifade etmek üzere kullanılmaktadır. Bu denli farklı düşünür veya düşünce okulunun bir arada sınıflandırmasının sebebi ise, belli müşterek kavram ve fikirlere sahip olduklarının ya da iktisat disiplininin ortodoksisine veya anaakımına karşı çıktıklarının kabul edilmesidir. Heterodoksiyi bu şekilde belli kavram ve fikirler üzerinden veya ortodoksinin veya anaakımın reddedilmesi üzerinden ele alan bu tanımlar heterodoksinin yalnızca entelektüel veçhesine vurgu yapmakta ve iktisat disiplininin değişen yapısını yansıtmamaktadır. Bu çalışmanın amacı ise, heterodoks iktisadın saygınlık ve nüfuz ekseninde ele alınması gereken sosyolojik bir kategori olduğunu vurgulamak ve sözü edilen düşünür ya da düşünce okullarının neden heterodoks olarak nitelendirildiklerini tespit etmektir.

Anahtar Kelimeler: Heterodoks iktisat, Entelektüel Tanım, Sosyolojik Tanım
Heterodox Economics as a Sociological Category

Abstract

The term of heterodox economics has been used to state such thinkers as Veblen, Marx, Robinson, Sraffa -even sometimes Keynes and Hayek- and such schools of thought as post-Keynesian economics, Marxist economics, Sraffian (neo-Ricardian) economics, structalist economics, institutional economics, social economics and evolutionary economics. Such diverse thinkers and schools of thought are classified together because it's accepted that they either have some common concepts and ideas, or reject the orthodoxy or mainstream of economics. But these definitions discuss heterodoxy in terms of particular concepts and ideas or rejection of orthodoxy or mainstream emphasise merely the intellectual aspect of heterodoxy and doesn't represent the changing structure of economics. The aim of this paper is to emphasise that the heterodox economics is a sociological cathegory which has to be discussed in the context of respect and influence, and determine why these thinkers of schools of thought aforementioned are designated as heterodox.

Keywords: Heterodox Economics, Intellectual Definition, Sociological Definition

\section{Giriş}

İktisat literatüründe, iktisadi sistemin işleyişini ve iktisadi sistem ile toplumsal yaşam arasındaki ilişkiyi açıklamayı amaçlayan çeşitli yaklaşım ve teoriler bulunmaktadır. Bu düşünce okullarının veya yaklaşımların nitelendirilmesi konusunda "orijinal", "eski", "neo", "yeni", "modern", "geleneksel", "post" gibi ön eklerin veya "klasik", "kurumcu”, "tarihçi", "feminist", "söylemsel" ve "davranışsal" gibi sıfatların kullanıldığı görülmektedir. Bunun yanı sıra bu düşünce okulları ve yaklaşımlar "Marksist", "Keynesyen", "Ricardocu", "Walrasyan", "Marshallyan" gibi bu yaklaşım ve teorileri ortaya koyan isimlerle veya "Alman", "Ingiliz", "Avusturya" gibi belli geleneklerle anılmaktadır. Ancak daha genel bir çerçeveden bakıldığında tüm bu düşünce okullarını sınıflandırmak amacıyla "anaakım", "ortodoks" ve "heterodoks" gibi sıfatlar tercih edilmektedir.

Bu çerçevede belli yaklaşım ve teorileri ifade etmek üzere anaakım ve ortodoks iktisat terimleri -hatalı bir biçimde genellikle eşanlamlı olarak- kullanılmaktadır. Bu şekilde bir tanımlamaya gidilmesindeki amaç iktisat disiplininin ön planda olan yaklaşımlarına anaakımını- ve en yakın dönemde disipline hâkim olan yaklaşıma -ortodoksi- işaret etmektir.

\footnotetext{
${ }^{1}$ Dr. Öğr. Üyesi, Aksaray Üniversitesi, Spor Bilimleri Fakültesi, Spor Yöneticiliği Bölümü. husnubilir@aksaray.edu.tr, yazar ORCID bilgisi: https://orcid.org/0000-0001-9602-8267.
} 
Heterodoks iktisat ise bu terimler üzerinden genellikle "olumsuz" anlamda ele alınmakta ve anaakım iktisadın ya da ortodoks iktisadın reddedilmesi olarak tanımlanmaktadır. Bu tanım doğrultusunda heterodoks iktisatçıların yegâne ortak özelliklerinin, anaakım ya da ortodoks iktisada karşı çıkmaları olduğu ifade edilmektedir. Heterodoks iktisat olumlu anlamda ise, heterodoks iktisatçıların ya da düşünce okullarının paylaştıkları müşterek noktalar üzerinden tanımlanmaktadır. Dolayısıyla her iki tanımda da heterodoks iktisat genel itibariyle entelektüel bir kategori olarak ele alınmakta ve iktisat disiplinindeki saygınlık, nüfuz ve güç ilişkileri üzerine inşa edilen sosyolojik boyutu göz ardı edilmektedir.

Bu çalışmanın amacı da, heterodoks iktisat teriminin belli bir yaklaşımı ya da kümeyi örneğin anaakım iktisadı veya ortodoks iktisadı- reddeden olumsuz bir kategori olarak ele alınmaması gerektiğini, daha ziyade sosyolojik bir kategori olduğunu vurgulamaktadır. Bu doğrultuda öncelikle heterodoks iktisadın "entelektüel" tanımlamalarına göz atılacak, daha sonra heterodoks iktisadın tanımlanmasında saygınlık, nüfuz ve güç faktörlerinin rolüne değinilecektir. Böylelikle belli düşünür ve düşünce okullarının neden "anaakım" veya "heterodoks" olarak nitelendirilmeleri gerektiği açıklanacaktır.

\section{Heterodoks İktisadın Entelektüel Tanımları}

Heterodoks iktisat muhtelif düşünürleri ve düşünce okullarını ifade eden ve farklı şekillerde tanımlanan çok-boyutlu bir kavramdır. Heterodoks iktisadın literatürde farklı şekillerde tanımlanmasının sebebi ise, iktisatçıların bu terimi farklı şekillerde ele almalarıdır. Bu çerçevede heterodoks düşünce geleneğinin yapı taşı olarak ontolojik düşünce (Nelson, 2003; Lawson, 2006; Caldwell, 2009; Lee, 2009), metodolojik benzerlikler (Dow, 2004, 2008), anaakıma veya ortodoksiye itiraz (Colander vd. 2004; Lavoie, 2006; Dequech, 2007, Holcombe, 2008; Meador, 2009; Lee, 2011, 2012) gösterilmektedir.

Bununla birlikte heterodoks iktisat terimi günümüzde genellikle anaakım veya ortodoks iktisat üzerinden -bu yaklaşımlardan ayrışan özellikleri bakımından- tanımlanmakta ve "muhalif" ve "diğer" düşünür ve düşünce okullarını nitelemek üzere kullanılmaktadır. Dolayısıyla "heterodoks" terimi bilhassa neoklasik iktisadi analizi eleştiren ve bu nedenle anaakım ve ortodoksi dışında kalan "diğerleri"ni imlemektedir². Örneğin heterodoks iktisat terimini ilk kullanan isim olan Allan Gruchy Modern Economic Thought (Modern iktisadi Düşünce) (1947) başlıkı kitabında bu terimi -aslında kurumcu iktisadı kastederek- Veblen geleneğinden gelen iktisatçıları ifade etmek üzere kullanmıştır ${ }^{3}$. Joseph Dorfman da (1970) heterodoks iktisadi düşüncenin ortaya çıkışında, İngiliz klasik iktisadi düşünce geleneğinin kısıtlayıcı yapısını eleştiren ve daha geniş bir bakış açısı öneren Alman Tarihçi Okulu'nun önemli bir paya sahip olduğunu belirtmiş ve heterodoks düşünce geleneği ifadesini Francis A. Walker,

\footnotetext{
2 Bu bakımdan, Mearman'a (2012: 420) göre heterodoks iktisadın önemli bir özelliği, heterodoks iktisadın, onu marjinalleştirmeye çalışan anaakım iktisatçılar tarafından değil de büyük ölçüde heterodoks iktisatçılar tarafından yaratılmış olmasıdır; diğer bir ifadeyle, güçlü tarafından yaratılan bir "Diğeri” olmaktansa, kendisini kendi terimleriyle "Diğeri" olarak tanımlamıştır. Backhouse (2004), Colander vd. (2004), Dequech (2007) ve Wrenn (2007b) ise heterodoks iktisadın temel unsurunun, heterodoks iktisatçıların kendilerini bu şekilde tanımlamaları olduğunu savunmaktadır.

${ }^{3}$ Gruchy (1947: vii) Veblen, Commons, Mitchell ve Clark'ın çalışmalarıyla ortaya çıkan heterodoksinin sonraki neslinin, düşüncelerini Veblen'in aksine "kurumcu iktisat" olarak tanımlamadıklarını, daha ziyade "sosyal", "deneysel" ve "kolektif" gibi terimleri tercih ettiklerini belirtmektedir.
} 
John A. Hobson, Thorstein B. Veblen, Wesley C. Mitchell, John R. Commons gibi iktisatçıların katkılarını tanımlamak üzere kullanmıştır ${ }^{4}$.

Dolayısıyla heterodoks iktisadın ilk olarak Veblen ekseninde ele alınan ve iktisattaki hâkim düşünce geleneğine alternatif bir bakış açısı öneren iktisatçıları işaret etmek üzere kullanıldığı söylenebilir. Günümüzde heterodoks iktisat terimi, bu çerçevede, daha geniş bir kitleyi ve yaklaşımlar bütününü ifade etmektedir. Örneğin post-Keynesyen iktisat, Marksist iktisat ve Marksist düşünce okulları -örneğin neo-Marksist bağımlılık teorileri, post-Marksizm, analitik Marksizm, yapısalcı Marksizm vb.- Sraffacı (neo-Ricardocu) iktisat, Avusturya iktisadı, yapısalcı iktisat, kurumcu iktisat, sosyal iktisat, söylemsel iktisat ve evrimci iktisat gibi farklı düşünce okulları günümüzde heterodoks iktisat kapsamında değerlendirilmektedir. Bu bakımdan Lee'ye (2011: 544) göre heterodoks iktisat, anaakım iktisatçılar tarafından hiç düşünülmeden reddedilen iktisadi teoriler bütününü ve kendilerini böyle tanımlayan ve heterodoks teoriler arasında rekabet edebilirliği ve kıyaslanamazlığı reddetmeden bu teorilere yönelik çoğulcu bir yaklaşım benimseyen heterodoks iktisatçılar bütününü ifade etmektedir. Heterodoks iktisadın çoğulcu yapısını vurgulayan Mearman da (2011) kendilerini heterodoks iktisatçı olarak tanımlayan iktisatçıların iktisat konusundaki temel inançlarının farklılaştığını ve grubun temel üyelerinin pek çok konu üzerinde görüş birliğine sahipken, periferide yer alan üyelerin hem kendi aralarında hem de temel üyelerle pek çok konuda anlaşmazlığa düştüklerini savunmaktadır ${ }^{5}$. Hands (2015: 63) ise merkez-periferi ayrımını anaakım-heterodoks iktisat bağlamında kullanmakta ve anaakım dışında kendilerini belli bir heterodoks okulun üyesi olarak tanımlama eğilimi söz konusu olduğunu; yani merkezde hâkim bir neoklasik okul ve periferide de çok sayıda farklı ancak bağımsız ve bilinçli bir şekilde tanımlanan heterodoks okullar olduğunu ileri sürmektedir. Benzer şekilde Davis de (2018) merkezi ortodoks, periferiyi ise heterodoks iktisat olarak ele alarak, heterodoks iktisadın diğer disiplinlere daha yakın olduğunu ve heterodoks kavram ve teorilerin disiplin açısından "yabancı" içeriklere sahip olduklarını ifade etmektedir.

Dolayısıyla heterodoks iktisadın farklı teorik konumlara ve farklı odak noktalarına sahip düşünce okullarından oluştuğu ve farklı teorileri, bireyleri ve grupları kapsadığı söylenebilir ${ }^{6}$ (Lawson, 2006; Wrenn, 2007a; Slade-Caffarel, 2019). Bu denli farklı görüş ve yaklaşımın neden "heterodoks" olarak adlandırıldıkları ve dolayısıyla bu görüş ve yaklaşımların ortak noktasının ne olduğu konusu ise tartışmalıdır. Bu bakımdan literatürde heterodoks iktisat genel olarak iki şekilde tanımlanmaktadır: entelektüel tanım ve sosyolojik tanım. Entelektüel tanım, iktisatçıları kavramsal kriterler çerçevesinde sınıflandırmaktadır; bu kriterler iktisatçıları bir araya getiren unsurlar olabileceği gibi (olumlu entelektüel tanım), bir şeye karşı birleşmelerini sağlayan kavramlar da olabilmektedir (olumsuz entelektüel tanım).

\footnotetext{
${ }^{4}$ Dorfman (1970: 21) Adam Smith'in de kendi dönemi için heterodoks bir iktisatçı olduğunu ileri sürmektedir. Benzer şekilde, Jo da (2016) heterodoks iktisadı klasik politik ekonominin devamı olarak ele almakta ve Marx, Veblen ve Keynes'i heterodoks iktisadın öncüleri olarak nitelendirmektedir.

${ }^{5}$ Bu çerçevede heterodoks iktisadın çoğulcu olduğunu savunan çalışmalar için bkz. Lawson, 1997; Dow, 2000, 2008; Garnett, 2006; Davis, 2008. Heterodoks iktisadın çoğulcu olmadığını savunan çalışmalar için ise bkz. Colander, 2007; Holcombe, 2008.

6 Dobusch ve Kapeller'e (2012: 1036) göre ise heterodoks iktisat tam anlamıla tutarlı olmayan ve kolayca tanımlanamayan farklı, neoklasik-olmayan düşünce okullarının bir bileşimidir. Heterodoks iktisadı mevcut ortodoksolmayan düşünce okullarının sentez bir ürünü olarak tanımlayan diğer çalışmalar için bkz. Sherman, 1987; Dugger, 1989; Sawyer, 1989; Arestis, 1992.
} 
Olumlu entelektüel tanımlar, heterodoks iktisatçılar ya da düşünce okulları arasında belli müşterek noktalar bulunduğunu ileri sürmektedir. Bu müşterek noktalar arasında ise insanın toplumsal bir varlık olduğunun vurgulanması, iktisadi sürecin karmaşık ve evrimsel bir süreç olduğunun vurgulanması gösterilmektedir. Örneğin heterodoks iktisadın entelektüel kökenlerinin heterodoks post-Keynesyen-Sraffacı, Marksist-radikal, kurumcu-evrimci, sosyal, feminist ve ekolojik iktisat geleneklerine dayandığını belirten Lee'ye (2012: 340) göre tüm bu geleneklerin müşterek özelliği birikim, adalet, sınıf, cinsiyet ve ırk arasındaki toplumsal ilişkiler ve iktisadi-toplumsal yeniden üretim gibi konuları vurgulamalarıdır ${ }^{7}$. Davis'e $(2007,2008)$ göre ise heterodoks yaklaşımları tanımlayan üç özellikten söz edilebilir: a) Bireyler atomist olmaktan ziyade, toplumsal bir yapı içerisinde yer almaktadırlar; b) iktisadi süreç mekanik değil evrimseldir; c) bireyler ve sosyo-ekonomik yapılar arasında karşılıklı bir ilişki söz konusudur. Lavoie'ye (2006: 7-12) göre ise heterodoks iktisadın temel karakteristikleri realizm, organiklik, prosedürel rasyonalite, üretim, büyüme ve devlet müdahalesidir ${ }^{8}$. Rosser (2011) ise kompleksite teorisinin heterodoks iktisadın temellerini sağladığını ileri sürerken, Dow (2000) heterodoks görüşlerin açık sistemler koşuluna dayandığını kabul etmektedir.

Mearman'a (2007: 3-4) göre ise heterodoks iktisadın temel özellikleri arasında şunlar sayılabilir: íktisadın anlaşılabilmesi açısından metodoloji önemlidir; insan eylemleri toplumsaldır ve tamamen rasyonel olmaktan ziyade, alışkanlıklar, rutinler, kültür ve gelenekler tarafından yönlendirilmektedir; iktisadi sistemler karmaşıktır, evrilen bir yapıya sahiptir ve tahmin edilemezdir; hem bireysel hem de toplulaştırıcı teoriler kullanışıdır ve bunlar birlikte ele alınmalıdır; tarih ve zaman önemlidir; tüm iktisat teorileri hata yapabilir; çoğulculuk savunulmaktadır; formel matematiksel ve istatistiksel yöntemler yegâne ve üstün yöntemler olmamalı ve diğer yöntemlerle birlikte ele alınmalıdır; olgular ve değerler birbirlerinden ayrılamaz; iktisadi çıktıların belirlenmesinde güç unsuru önemlidir.

Dolayısıyla olumlu entelektüel tanımlar heterodoks iktisatçılar ve düşünce okulları arasındaki müşterek noktaları ön plana çıkarmakta ve sınıflandırmayı bu kriter çerçevesinde yapmaktadır. Ancak Dequech'in (2007) belirttiği üzere, heterodoks iktisadın olumlu entelektüel tanımı iktisatçıları uyumlu ve tutarlı bir şekilde bir araya getirme konusunda başarılı olamamıştır, bu nedenle halihazırda literatüre hâkim olan yaklaşım heterodoks iktisadın "anaakım veya ortodoks olmayan" şeklinde tanımlandığı olumsuz entelektüel tanımdır. Olumsuz entelektüel tanımlarda heterodoks iktisat "ne olduğu"ndan ziyade "ne olmadığı" üzerinden ele alınmaktadır, zira heterodoks iktisatçıların ve okulların anaakım ya da ortodoks iktisadı reddetmek dışında müşterek bir noktaya sahip olmadıkları düşünülmektedir. Örneğin Lavoie (2006) ve Lee'ye (2012) göre, heterodoks iktisatçılar argümanlarını anaakım teori dâhilinde eleştirel bir şekilde geliştirdikleri için, heterodoks iktisatçılar arasındaki yegâne ortak nokta anaakım iktisada karşı çıkmalarıdır ${ }^{9}$. Bu çerçevede Lee'ye $(2011,2012)$ göre heterodoks iktisat ile anaakım iktisat arasındaki esas fark, heterodoks iktisadın tedarik süreçlerini toplumsal bir olgu olarak ele almasıdır.

\footnotetext{
${ }^{7}$ Bu çerçevede Lee'ye (2009) göre heterodoks iktisadın ayırt edici metodolojik özelliği, yoğun matematiksel formalist metodolojiye karşı çıkılmasıdır.

${ }^{8}$ Lavoie (1992) başka bir çalışmasında ise, heterodoks iktisadı organikliğe ve prosedürel rasyonaliteye bağı kalmak ve üretime odaklanmak olarak tanımlamaktadır.

${ }^{9}$ Ancak Lee'ye (2012: 339) göre heterodoks iktisat anaakım iktisada muhalif bir şekilde değil, ona pozitif bir alternatif olarak tanımlanmaktadır. Dolayısıyla eğer anaakım iktisat ortadan kalkarsa, heterodoks iktisat da etkinliğini yitirecektir; bu bağlamda heterodoks perspektiften anaakım iktisat yok edilmesi gereken bir düşman değildir, toplumsal tedarik süreci konusunda anlamlı veya açıklayıcı bir güce sahip olmayan fikirler ve argümanlar bütünüdür.
} 
Benzer şekilde Lawson da (2006) heterodoks iktisadı, anaakım iktisat ile farkı üzerinden tanımlamaktadır: Lawson'a göre heterodoks iktisat ile anaakım iktisat arasındaki asıl fark, anaakımın matematiksel modelleme konusunda ısrarcı olmasıdır, bu bakımdan heterodoks iktisat, analitik açıdan, anaakım-olmayan olarak tanımlanabilir:

"Heterodoks gelenekler ile modern anaakım arasındaki ayrımların sebebi ontoloji olabilir, örneğin eğer ontolojik bağlııklar post-Keynesyenleri, kurumcuları, feminist iktisatçıları ve diğerlerini heterodoks olarak tanımlarsa, heterodoks gelenekleri ayrıştıran şey de kendilerine özgü esas yönelimleri, ilgileri ve vurgularıdır, yanıtları veya ilkeleri değil" (Lawson, 2006: 499, vurgular Lawson'a aittir).

Holcombe'ye (2008: 51-52) göre de heterodoksi, genel olarak kabul edilen anaakım veya ortodoksinin dışında kalan yöntemleri, yaklaşımları ya da düşünce okullarını ifade etmektedir. Colander vd. de (2004:491) heterodoks teriminin genellikle ortodoksiye referansla, yani ortodoksiye karşıt olarak tanımlandığını ifade etmekte ve heterodoks iktisadı tanımlayan başka bir birleştirici unsurdan söz edilemeyeceğini ileri sürmektedir. Davis (2009) ise merkez-periferi ayrımı yaparak, iktisadın merkezi ilkelerini ve kavramlarını ortodoks olarak tanımlarken, iktisadın heterodoks periferisini ise merkezin dışında kalan ancak yine de iktisadın sınırlarıyla bir şekilde ilişkisini sürdüren ilkeler ve kavramlar anlamında tarif etmektedir ${ }^{10}$. Anaakım iktisadı mantıksal pozitivizm üzerinden, heterodoks iktisadı da anaakım-olmayan olarak tanımlayan Meador'a (2009) göre ise heterodoks iktisat ve anaakım iktisat, Foucaultcu anlamda, tamamen farklı epistemelere sahiplerdir.

\section{Heterodoks İktisat: Sosyolojik Bir Tanım Gerekliliği}

Dolayısıyla literatürdeki yaygın tanımın, heterodoks iktisadı anaakım veya ortodoks iktisada -en azından bazı fikirlerine- muhalefeti üzerinden ele alan "olumsuz" entelektüel tanımlar olduğu söylenebilir. Ortodoks iktisat ve anaakım iktisat eşanlamlı olarak ele alındığında heterodoks iktisadı ortodoks ya da anaakım iktisadın karşıtı olarak tanımlamak mümkündür. Ancak anaakım iktisat ile ortodoks iktisat eşanlamlı olarak ele alınmadığında heterodoks iktisadın bu şekilde tanımlanması daha tartışmalı hale gelmektedir. Zira bu durumda ortodoks iktisat ile anaakım iktisat arasında bir ayrım yapılması gerekmektedir. Bu doğrultuda, öncelikle anaakım iktisat ve ortodoks iktisat sosyolojik açıdan tanımlanmalı ve buna paralel bir biçimde heterodoks iktisat da sosyolojik bir kategori olarak ele alınmalıdır.

Sosyolojik tanımlar entelektüel tanımın aksine belli kavram ve fikirlere değil, güç ilişkilerine ve saygınlık ve nüfuz gibi faktörlere odaklanmaktadır. Bu çerçevede sosyolojik tanımlar anaakımı bir kavram ve/veya yöntem üzerinden değil, bir topluluk ve bu topluluğun iletişim ağları bağlamında ele almaktadır. Örneğin Dequech (2007: 281) anaakım iktisadı "en saygın üniversitelerde ve yüksekokullarda öğretilen, en saygın dergilerde yayımlanan, en önemli araştırma vakıfları tarafından desteklenen ve en saygın ödülleri kazanan" iktisat olarak tanımlamaktadır. Diğer bir ifadeyle, Dequech'e (1999: 422) göre anaakım iktisat "öğretildiği üniversitelerin ve yayımlandığı dergilerin saygınlığıyla desteklenen bir bilgi türü" olarak ele alınabilir.

Dolayısıyla Dequech (2007) anaakım iktisadı saygınlık ve nüfuz temelinde sosyolojik açıdan tanımlamaktadır ve bu tanım, saygın üniversitelerde ve yüksekokullarda öğretilen fikirleri ve bu fikirlerin diğer, daha az saygın yerlerdeki destekçilerini kapsamaktadır. Bu bağlamda, anaakım

${ }^{10}$ Ancak Davis iktisat tarihinde ortodoks ve heterodoks düşünce okulları ve yaklaşımlar değiştiği için, merkez ve periferi ilkelerin ve kavramların da değiştiğini eklemektedir. 
iktisadı sosyolojik açıdan tanımlamak, farklı düşünce okullarının ve yaklaşımların anaakıma dâhil olmasını sağlamaktadır, böylelikle anaakım iktisat spesifik bir düşünce okulundan ziyade dünyanın önde gelen yükseköğretim kurumlarında öğretilen düşünce ve yaklaşımları ifade eder hale gelmektedir. Bu bakımdan sosyolojik tanımlar, Mearman'ın (2012: 415) belirttiği gibi, grup üyeliklerine, kültür topluluklarına, iletişim ağlarına ve bu gruplarla alakalı gücün konumuna ve uygulanmasına odaklanmaktadır ${ }^{11}$.

Sosyolojik açıdan ortodoks iktisat ise, iktisadi düşünce geleneğine hâkim olan en son yaklaşımı ifade etmektedir; bu bakımdan günümüzde iktisat disiplininin ortodoksisi neoklasik iktisat tarafından temsil edilmektedir (Colander vd., 2004; Dequech, 2007; Black vd., 2013; Hands, 2015). Bu tanımlar doğrultusunda anaakım iktisadın ortodoks iktisattan daha kapsamlı bir ifade olduğunu ve ortodoks iktisadın anaakımın bir parçası olduğunu söyleyebiliriz, ancak anaakım iktisat ortodoks iktisattan -yani neoklasik iktisattan- ibaret değildir. Anaakım içerisinde neoklasik iktisadı çeşitli açılardan eleştiren davranışsal iktisat, deneysel iktisat, nöroiktisat, yeni kurumcu iktisat ve klasik-evrimci-davranışsal oyun teorileri gibi farklı yaklaşımlar da yer almaktadır. Bu bakımdan anaakım iktisat ile ortodoks iktisat aynı şeyi ifade etmemektedir, anaakım iktisat ortodoks iktisadı da bünyesinde barındıran ve belli bir güce, saygınlığa ve nüfuza sahip düşünce okullarını ve yaklaşımları ifade etmektedir.

Anaakım iktisat ve ortodoks iktisat bu şekilde sosyolojik bir kategori olarak ele alındığında, heterodoks iktisadın da sahip olduğu saygınlık ve nüfuz temelinde sosyolojik açıdan tanımlanması gerekmektedir. Bu çerçevede heterodoks iktisatçılar topluluğu, anaakım iktisatçılar topluluğundan ayrıdır ve bağlamda heterodoks düşünce okulları kendi dergilerine, iletişim ağlarına, örgütlerine ve akademik kurumlarına sahiplerdir. Benzer şekilde Lee de (2012: 344-348) hem anaakım iktisadın hem de heterodoks iktisadın kendi dergilerine ve departmanlarına, araştırma programlarına sahip olduklarını ve her iki taraftaki en iyi dergilerin, departmanların ve önde-gelen araştırmaların diğer tarafta saygı görmediğini belirtmektedir. Bu çerçevede Mearman'a göre (2012: 416) heterodoks iktisat birliğinin oluşması ve gelişimi, kendilerini bir şekilde anaakımdan farklı olarak ifade etmek isteyen ve belli müşterek inançlara sahip bir iktisatçılar grubu için bir kurumsal yapı ve bir savunma organı yaratmıştır.

Dolayısıyla heterodoks iktisadın sosyolojik bir kategori olarak ele alınması, iktisat disiplinindeki güç unsuruna dikkat çekmekte ve bir tarafta nispeten daha fazla güce ve dolayısıyla daha fazla saygınlığa sahip anaakım iktisat/iktisatçılar, diğer yanda ise nispeten daha az güce ve dolayısıyla daha az saygınlığa sahip heterodoks iktisat/iktisatçılar ayrımına yol açmaktadır. Ayrıca heterodoks iktisadın bu şekilde güç, saygınlık ve nüfuz faktörleri temelinde tanımlanması daha esnek bir tanım yapılmasına olanak sağlamakta ve iktisat disiplininin değişen ve evrilen yapısına uygun düşmektedir. Zira Dequech'in (2007: 294-295) belirttiği gibi, heterodoks iktisat belli bir zamanda müşterek teorik, metodolojik veya politik özelliklere sahip olabilir de olmayabilir de; veya bu tür müşterek özelliklere sahipse de bu özellikler zamanla değişebilir. Ayrıca iktisat disiplininde bir dönem anaakım olan bir düşünür/yaklaşım daha sonraki dönemlerde heterodoks iktisat düşünürleri/okulları arasında zikredilmeye başlayabilir; ya da tam tersi. Örneğin 1900'lü yılların başlarında bilhassa Amerika'da anaakım olan kurumcu iktisat günümüzde o dönemki etkinliğini yitirmiş ve heterodoks düşünce okulları arasında ele

\footnotetext{
${ }^{11}$ Mearman (2012) bunun yanın da psikolojik ve empirik/biyolojik tanımları da ele almaktadır. Mearman'a göre son zamanlarda mevcut grupların karakteristiklerini araştıran empirik çalışmalar da ortaya çıkmıştır. Bazı durumlarda ise, bu çalışmalar biyolojik bir perspektifi yansıtmaktadır; örneğin heterodoks iktisatçıları "gelişen popülasyon" olarak ele almaktadırlar.
} 
alınmaya başlamıştır. Mearman'a (2012: 416) göre bu durumun bir diğer örneği de Keynes'in fikirleridir; Keynes'in fikirleri bir dönem anaakım iken, daha sonra gözden düşmüştür.

Diğer yandan heterodoks iktisadın -aynı zamanda ortodoks ve anaakım iktisadın dasosyolojik bir kategori olarak ele alınması ortodoks iktisadı eleştiren iktisatçı ve yaklaşımların illa heterodoks olarak nitelenmemesine ve anaakıma dâhil edilebilmesine imkân tanımaktadır. Zira yalnızca entelektüel bir kriter üzerinden yapılan tanımlamalar iktisat disiplininde son dönemde ortaya çıkan davranışsal iktisat, deneysel iktisat, evrimci iktisat ve nöroiktisat gibi yaklaşımların sınıflandıııması konusunda kafa karışıklığına sebebiyet vermektedir. Örneğin Hands'e (2015: 63-64) göre bu yeni araştırma sahaları "dar neoklasik anlamda 'ortodoks' değillerdir -standart neoklasik teoriyle çelişen düzensizlikler üretmekte ve genellikle iktisadi davranışı neoklasik-olmayan yollarla tanımlamaktadırlar-, ancak geleneksel anlamda 'heterodoks' da değillerdir; Marksist veya kurumcu, Avusturya (iktisadı) vs. değillerdir ${ }^{12}$."

Bu kafa karışıklığının sebebi ise, söz konusu yaklaşımların ortodoksiyle çelişen sonuçlara ulaşmaları ancak geleneksel anlamda heterodoks oldukları kabul edilen kurumcu iktisat, Marksist iktisat, sosyal iktisat ya da evrimci iktisat gibi anaakım dışında kalmamalarıdır, diğer bir ifadeyle göz ardı edilmemeleridir. Bu yeni araştırma sahalarında çalışan düşünürler önde gelen anaakım dergilerde yayın yapmakta, dünyanın önde gelen üniversite, enstitü ve araştırma laboratuvarlarında görev yapmakta ve yapmış oldukları çalışmalar sonucunda Nobel iktisat ödülüne layık görülmektedirler ${ }^{13}$.

$\mathrm{Bu}$ nedenle bu yaklaşımlar anaakım olarak nitelendirilmekte ve heterodoks iktisadın kapsamına dâhil edilmemektedir ${ }^{14}$. Bu çerçevede ekonofizikçileri, davranışsal ve deneysel iktisatçıları ve kompleksite iktisatçılarını anaakım içerisinde değerlendiren Colander'a (2007) göre bu fikir ve yaklaşımlar, ortodoks düşünceye göre "heterodoks" fikir ve yaklaşımlar olsalar da, anaakım olarak değerlendirilebilirler. Benzer şekilde Rabin (2002), Sent (2004) ve Heukelom'a (2014) göre de davranışsal iktisat anaakım iktisat olma yönünde ilerlemektedir.

Dolayısıyla ortodoks iktisadı en azından belli noktalar -örneğin rasyonalite, kişisel-çıkar ve denge varsayımları- bakımından eleştiren bu yaklaşımlar anaakım iktisat içerisinde yer almaktadır, zira eleştirilerini yine anaakım iktisadın diliyle yani matematiksel ve formel bir biçimde sunmaktadırlar. Diğer bir ifadeyle, bir fikir veya yaklaşımın heterodoks olmasına yol açan unsur, ortodoks iktisada eleştiri yöneltmesi değildir, bu eleştiriyi sunuş biçimidir ${ }^{15}$.

\footnotetext{
12 Eren ve Uysal (2017: 139) ise davranışsal iktisat, deneysel iktisat, nöroiktisat, evrimsel iktisat ve kompleksite iktisadını yeni heterodoks iktisat olarak nitelendirdikleri akıma dâhil etmektedirler.

${ }_{13}$ Örneğin davranışsal iktisadın kurucuları arasında gösterilen Daniel Kahneman -Amos Tversky ile birlikte yapmış oldukları çalışma sebebiyle- ile deneysel iktisadın kurucuları arasında gösterilen Vernon Smith 2002 yılında Nobel iktisat ödülünü paylaşmışlardır.

${ }^{14}$ Davis'e (2008) göre ise davranışsal iktisat, kurumcu iktisat ve oyun teorisi, neoklasik ortodoksiyle çelişen temel varsayımlara sahiptir ve dolayısıyla heterodoks olarak nitelendirilmelidir; Davis'in bu çerçevede önerdiği terim "anaakım heterodoks" tur.

${ }^{15}$ Bu noktada bu durumun istisnaları olduğu vurgulanmalıdır. Örneğin Sraffacı iktisadın ve analitik Marksistlerin de matematiği yoğun biçimde kullandıkları söylenebilir. Dequech (2007: 290) ise bu noktada, matematiksel modeller inşa etmeyen ancak önemli bir saygınlığa ve etkiye sahip iki iktisatçının matematiksel formalizasyon konusunda istisna teşkil ettiklerini vurgulamaktadır: Nobel ödüllü iktisatçılar Ronald Coase ve Douglass North. Colander’a (2000: 136-137) göre ise David Romer, Buz Brock, Richard Thaler, William Baumol, George Akerlof, Joseph Stiglitz, David Card, Alan Krueger, Paul Krugman, Ken Arrow, Amartya Sen, Thomas Shelling gibi modern iktisatçılar neoklasik çerçevenin dışında işler yapmalarına rağmen, anaakım iktisatçılar arasında yer almaktadırlar. Backhouse'a (2004: 267) göre ise Stiglitz geleneksel formel aletler kullanarak, piyasa-karşıtı argümanlar geliştirmiştir; bu bakımdan Stiglitz anaakım gözükmesine rağmen, bir bakımdan da değildir.
} 
Anaakım iktisatçıların diliyle ifade edilmeyen eleştiriler saygınlık kazanamamakta, dünyanın önde gelen üniversitelerinde müfredata dâhil edilmemekte ve önde gelen dergilerde yayınlanmamaktadır; sonuç olarak bu eleştiriler büyük ölçüde göz ardı edilmektedir ${ }^{16}$.

Dolayısıyla yapılan eleştirilerin anaakımın dikkatini cezbetmesi ve belli bir saygınlığa erişebilmesi, diğer bir ifadeyle heterodoks fikirlerin ya da iktisatçıların anaakım tarafından kabul görmeleri için anaakımın dilini kullanıp kullanmamaları gerektiği konusu ön plana çıkmaktadır. Zira Lee'ye (2012: 343-344) anaakım iktisatçılar kapalı bir entelektüel ortama sahiptirler ve kendi paradigmalarına duydukları güven heterodoks eleştirileri takip etmelerine engel olmaktadır ${ }^{17}$. Benzer şekilde Colander de (2010) iktisat bölümlerinde, dergi sıralamalarında, akademik iş kurallarında ve kurumlarında göze çarpan akademik statükonun gelecekte değişmesinin pek mümkün görünmediğini ifade etmektedir ${ }^{18}$. Bu nedenle, Colander'a (2007) göre, heterodoks fikirlerin anaakıma dâhil olabilmesi için, heterodoks iktisatçılar kullandıkları aletleri değiştirmeli ve fikirlerini formel bir şekilde daha sofistike matematik ve istatistik kullanarak ifade etmelidirler; diğer bir ifadeyle heterodoks iktisatçılar anaakım iktisatçıların diliyle konuşmak zorundadırlar. Bu doğrultuda Dow (2000) ve Fullbrook'a (2003) göre postKeynesyen iktisat, kurumcu iktisat, neo-Avusturya iktisadı, davranışsal iktisat, sosyal iktisat, feminist iktisat, Marksist/radikal iktisat gibi açık sistem yaklaşımını benimseyen ortodoksolmayan düşünce okulları anaakıma meydan okuyacak kadar güçlenebilirler ${ }^{19}$.

Literatürde daha önce heterodoks iktisat ile bağlantılı olarak ele alınan bazı konuların son dönemde anaakıma dâhil olmaları da heterodoks iktisatçıların hangi dili kullanmaları gerektiği tartışmasına örnek teşkil etmektedir, zira bu konular anaakıma dâhil olurken "anaakımlaştırılmakta" ve bu süreçte heterodoks iktisatçıların isimleri zikredilmemektedir ${ }^{20}$. Colander'a (2007) göre de son yıllarda anaakım iktisada dâhil olan ve uzun yıllar boyunca heterodoks iktisatçılar tarafından savunulan fikirler anaakıma heterodoks iktisat vasıtasıyla dâhil olmamıştır. Örneğin post-Keynesyen iktisatçılar tarafından vurgulanan belirsizlik unsurunu ifade edecek analitik araçlar yakın döneme dek geliştirilemediği için post-Keynesyen iktisat anaakımın dışında kalmıştır; ancak son dönemde matematik alanında kompleksite aletlerinin gelişmesiyle birlikte bu fikirler, post-Keynesyen iktisatçılara hiçbir atıf yapılmadan, anaakım iktisada dâhil olmuştur. Benzer şekilde, kurumcu iktisatçılar tarafından vurgulanan sosyo-ekonomik unsurlar ve kurumsal etkiler de, evrimci oyun teorisinin gelişimiyle birlikte anaakıma dâhil olmuş, ancak yine kurumcu iktisatçıların isimleri hiç anılmamıştır. Hands'e (2015: 70-71) göre de, son dönemde literatürde ele alınan konular ve tanımlanan anomaliler heterodoks iktisat geleneğinde çalışan iktisatçılar tarafından tespit edilmiş olsa da, bu yeni alanlarda çalışan iktisatçılar kendilerini heterodoks düşünce okulu içerisinde tanımlamamaktadırlar.

\footnotetext{
${ }^{16}$ Eren (2012) ise heterodoks iktisatçıların eleştirilerini farklı bir bağlamda ele almaktadır. Eren'e (2012: 2-3) göre, heterodoks iktisatçılar tarafından ortodoks iktisada yöneltilen eleştiriler, bir anlamda önceki yıllardaki ortodoks iktisatla ilgilidir, örneğin bu gün yerleşik iktisada getirilen eleştiriler, bir anlamda 30 yıl öncesinin yerleşik iktisadına yöneliktir. Bu husus da heterodoks eleştirilerin göz ardı edilmesine yol açabilir.

17 Davidson (2005) ise heterodoks iktisatçıların tek bir "genel teori" üzerinde birleşemedikçe, anaakım iktisatçıların dikkatlerini çekemeyeceklerini ve akademik dünyada kendilerine yer bulamayacaklarını ileri sürmektedir.

${ }^{18}$ Yapılan atıf analizleri, anaakım iktisatla bağlantılı akademik dergilerin heterodoks iktisatçıların katkılarını sistematik olarak göz ardı ettiklerini göstermektedir. Bkz. Cronin, 2010; Kapeller, 2010a, 2010b.

${ }^{19}$ Colander vd. (2004: 291) ise heterodoks iktisatçıların anaakım iktisat çerçevesinde çalışmayı reddettiklerini ifade etmektedir.

${ }^{20}$ Bu durum aynı zamanda, ortodoks iktisat ile heterodoks iktisat arasındaki merkez-periferi ilişkisinin esnediğinin bir göstergesi olarak da yorumlanabilir.
} 
Bu bakımdan heterodoks iktisat sosyolojik olarak anaakımdan farklı olarak tanımlandığında -yani daha az güce, saygınlığa ve nüfuza sahip olması anlamında- heterodoks iktisadın kapsamı daralacak ve günümüzde heterodoks iktisat, bazı saygın ve etkili neoklasik-olmayan yaklaşımları kapsamayacaktır ${ }^{21}$. Bu çerçevede günümüzde hetorodoks iktisat okulları içerisinde kurumsal iktisat, Alman tarihçi okul, Avusturya okulu, evrimci iktisat, post-Keynesyen iktisat, Marksist iktisat, söylemsel iktisat, feminist iktisat ve post-otistik iktisat sayılabilir. Benzer şekilde American Economic Association'ın Journal of Economic Literature (JEL) sınıflandırmasına göre de, mevcut heterodoks iktisat okulları arasında sosyalist okul, Marksist okul, Sraffacı okul, tarihçi okul, kurumcu okul, evrimci okul, Avusturya okulu, feminist iktisat ve sosyal iktisat yer almaktadır $^{22}$ (https://www.aeaweb.org/econlit/jelCodes.php?view=jel\#B).

Bu farklı yaklaşım ve geleneklerin heterodoks olarak nitelendirilmesinin sebebi, -kurumcu iktisat örneğinde olduğu gibi- bir dönem yüksek saygınlığa ve nüfuza sahip olsalar da, günümüzde bu yaklaşım ve düşünce geleneklerinin anaakım iktisat kadar saygın olmadıklarının düşünülmesi ve dünyanın önde gelen yükseköğretim kurumlarında öğretilmemeleri, anaakım iktisat doğrultusunda yayın yapan dergilerde yer almamaları ve heterodoks iktisatçıların önde gelen kurum ve üniversitelerde görev yapamamalarıdır (Jackson, 2018: 239). Bu çerçevede heterodoks iktisatçılar kendi topluluklarını kurmakta ${ }^{23}$, kendi dergilerini ${ }^{24}$ çıkarmakta ve belli üniversitelerin kadrolarında istihdam edilmektedirler. Dolayısıyla "heterodoks" olarak nitelendirilmek entelektüel bir meseleden ziyade, iletişim ağları, grup üyelikleri, kültür toplulukları ve bu topluluk ve iletişim ağlarıyla bağlantılı olarak güç, saygınlık ve nüfuz meselesidir ${ }^{25}$.

\section{Sonuç}

İktisadi düşüncenin en önemli veçhelerinden birisi terminolojinin sınıflandırılması ve bu terminolojiye tanımsal bir içerik sağlanmasıdır. Bu çerçevede iktisat disiplinindeki muhtelif düşünür ve düşünce okullarının sınıflandırılmasında "anaakım", "ortodoks" ve "heterodoks" gibi terimler tercih edilmektedir. Literatürde anaakım ve ortodoks iktisat genellikle eşanlamlı olarak kullanılmakta ve heterodoks iktisat da anaakıma ya da ortodoksiye -en azından belli kavram ve fikirler bağlamında- karşı çıkılması üzerinden tanımlanmaktadır.

\footnotetext{
${ }^{21}$ Ancak bu sosyolojik tanım çerçevesinde anaakım iktisattan dışlanan bazı fikir ve yaklaşımlar, Dequech'in (2007: 297298) belirttiği gibi, sosyoloji alanında saygın dergilerde yayımlanmaktadır, bu bakımdan heterodoks iktisadın bir bölümünün, entelektüel anlamda, anaakım (iktisat) sosyolojisinin bir parçası olduğu söylenebilir.

22 Lavoie (2015) ve Arslan (2017), heterojenlik, otonomi, sınırlı rasyonalite ve dengesizlik varsayımları nedeniyle ajantabanlı hesaplamalı iktisadı heterodoks iktisat okulları arasında ele almaktadırlar. Davis (2018) ise, heterodoks iktisat okulları arasına tabakalaşma iktisadını (stratification economics), ekolojik iktisadı ve "eski" davranışsal iktisadı da dâhil etmektedir.

${ }^{23}$ Heterodoks iktisatçılardan oluşan topluluklara The Association for Heterodox Economists (Heterodoks iktisatçılar Birliği) ve Australian Society of Heterodox Economics (Avustralyalı Heterodoks iktisatçılar Cemiyeti) örnek gösterilebilir (Wrenn, 2007b: 98).

${ }^{24}$ Heterodoks iktisat alanında yayın yapan önde gelen dergiler arasında American Journal of Economics and Sociology, Bulletin of Political Economy, Cambridge Journal of Economics, Economic Issues, Feminist Economics, International Journal of Social Economics, Journal of Heterodox Economics, Journal of Institutional Economics, Journal of Post Keynesian Economics, Review of Radical Political Economics sayılabilir.

${ }^{25}$ Bu çerçevede Mearman'a (2012: 411) göre feminist iktisatçılar bilhassa İngiltere ve Avrupa'da heterodoks toplumsal grupların nispeten daha az parçası olmuşlardır; Feminist Economics (Feminist iktisat) dergisi anaakım değerlendirmelerde yüksek sıralamaya sahiptir. Mayer (1998) ise Avusturya iktisadını, anaakım iktisadın bir tamamlayıcısı olarak ele almaktadır. Lee (2012: 344) ise Marksizmi, kurumcu iktisadı ve sol-görüşlü Keynesyenleri heterodoks iktisada dâhil etmemektedir. Wrenn (2007a) ise yeni kurumcu iktisadı da heterodoks düşünce okulları arasında saymaktadır.
} 
Bu çerçevede heterodoks iktisat günümüzde anaakıma ya da ortodoksiye eleştiri yönelten muhalif düşünür ve düşünce okullarını işaret edecek şekilde kullanılmaktadır, bu bakımdan heterodoks iktisat terimi günümüzde ilk olarak önerildiği anlamdan daha kapsayıcıdır. İlk olarak Veblen ve diğer kurumcu iktisatçıları ve bu gelenek doğrultusunda çalışan iktisatçıları işaret eden heterodoks iktisat günümüzde kurumcu iktisadın kökenlerinin dayandırıldığı Alman Tarihçi Okulu'ndan Marksist okullara, post-Keynesyen iktisattan söylemsel iktisada kadar geniş bir yelpazeyi ifade eden çoğulcu bir yapıya sahiptir.

$\mathrm{Bu}$ denli geniş bir yelpazenin birleştirici unsuru olarak ise, genel olarak, heterodoks iktisatçıların ve düşünce okullarının belli kavram veya fikirlere odaklanmaları (Dow, 2000, 2004, 2008; Lavoie, 1992, 2006; Mearman, 2007; Davis, 2007, 2008; Lee, 2009, 2012; Rosser, 2011) ya da belli kavram ve fikirlere -örneğin anaakım veya ortodoks iktisada- karşı çıkmaları gösterilmektedir (Colander vd. 2004; Lavoie, 2006; Dequech, 2007, Holcombe, 2008; Meador, 2009; Lee, 2011, 2012). Bu tanımlarda heterodoks iktisat entelektüel bir kategori olarak ele alınmakta ve belli kavram ve fikirler üzerinden bir sınıflandırma yapılmaktadır.

Ancak heterodoks iktisatçılar ve düşünce okulları arasında belli müşterek noktalar tespit etmeyi amaçlayan olumlu entelektüel tanımlar ya da heterodoks iktisadı anaakıma veya ortodoks iktisada -en azından belli noktalar bakımından- karşı çıkılması üzerinden tanımlayan olumsuz entelektüel tanımlar, her şeyden önce, iktisat disiplinindeki güç, saygınlık ve nüfuz unsurlarını göz ardı etmektedir. Sosyolojik tanımlar ise grup üyeliklerine, kültürlü topluluklara ve iletişim ağlarına ve bu gruplarla alakalı gücün konumuna ve uygulanmasına odaklanmaktadır. $\mathrm{Bu}$ çerçevede anaakım-heterodoks iktisat ayrımı saygınlık ve nüfuz unsurları temelinde yapılmaktadır. Bu doğrultuda anaakım iktisat dünyanın önde gelen yükseköğretim kurumlarında öğretilen düşünce ve yaklaşımları ifade eder hale gelmektedir, dolayısıyla anaakım iktisadın ayırt edici özelliği yüksek bir saygınlığa ve nüfuza sahip olmasıdır. Anaakım iktisat bu şekilde sosyolojik bir kategori olarak ele alındığında, heterodoks iktisadın da sosyolojik açıdan tanımlanması gerekmektedir.

Bu çerçevede heterodoks iktisatçılar topluluğu, anaakım iktisatçılar topluluğundan ayrıdır ve heterodoks düşünce okulları kendi dergilerine, iletişim ağlarına, örgütlerine ve akademik kurumlarına sahiplerdir. Böylelikle bir tarafta nispeten daha fazla güç ve dolayısıyla daha fazla saygınlık sahibi anaakım iktisat/iktisatçılar, diğer yanda ise nispeten daha az güç ve dolayısıyla daha az saygınlık sahibi heterodoks iktisat/iktisatçılar ayrımı ortaya çıkmaktadır.

Heterodoks iktisadın sosyolojik açıdan tanımlaması iktisat disiplininin değişen yapısına da uygun düşmektedir. İktisat değişen ve evrilen bir yapıya sahip olduğundan, iktisat literatüründe belli yaklaşım ve fikirler -kurumcu iktisat veya Keynes'in fikirleri örneğinde olduğu gibi -bazı dönemlerde anaakım olacak denli saygınlık ve nüfuza sahip iken, sonraki dönemlerde bu saygınlık ve nüfuzunu yitirmekte ve ikinci planda kalabilmektedir; veya tam tersi. Ayrıca anaakım ve heterodoks iktisat toplulukları yalnızca kendi içerisinde beslenmemekte ve karşılıklı olarak fikir alışverişinde bulunmaktadırlar.

Bu bağlamda sosyolojik tanımlar ortodoks iktisadı eleştiren iktisatçı ve yaklaşımların illa heterodoks olarak nitelenmemesine ve anaakıma dâhil edilebilmesine de olanak tanımaktadır. Günümüzde davranışsal iktisat, deneysel iktisat, nöroiktisat, yeni kurumcu iktisat, klasikdavranışsal-evrimci oyun teorileri gibi yaklaşımlar bu duruma örnek teşkil etmektedir. Ortodoks iktisadı- yani neoklasik iktisadı- rasyonalite, kişisel-çıkar ve denge varsayımları temelinde eleştiren bu yaklaşımlar günümüzde yüksek bir saygınlığa ve nüfuza sahiptir; bu yaklaşımlar dünyanın önde gelen üniversitelerinde öğretilmekte, önde gelen dergilerde yayın imkânına 
kavuşmakta ve bu alanlara özgü enstitü ve laboratuvarlar kurulmaktadır; hatta bu yaklaşımlara Nobel iktisat ödülleri verilmektedir. Bu nedenle bu yaklaşımlar ortodoks iktisada eleştiri yöneltseler de, anaakım iktisadın bir parçası haline gelmişlerdir; diğer bir ifadeyle söz konusu yaklaşımlar entelektüel açıdan heterodoks olsalar da, sosyolojik açıdan anaakıma dâhillerdir.

Bu yaklaşımların yüksek saygınlığa ve nüfuza sahip olmalarının yani anaakım iktisadın bir parçası olarak telakki edilmelerinin sebebi ise, anaakım iktisatçıların kullandıkları dili kullanmalarıdır; diğer bir ifadeyle bu yaklaşımlarda formel matematiksel ifade ve denklemler ön plana çıkmaktadır. Dolayısıyla bir zamanlar heterodoks olarak nitelendirilen fikirlerin günümüzde anaakıma dâhil olmalarının sebebi, sunulan eleştirilerin anaakım iktisatçıların dilini kullanmış olmasıdır. Bu fikirlerin anaakıma dâhil olmaları sırasında heterodoks iktisatçıların isimleri nadiren zikredilmektedir. Bu bağlamda heterodoks iktisadın bir seçimle karşı karşıya olduğu söylenebilir. Eğer heterodoks iktisat anaakım iktisada iyi bir alternatif teşkil edebilmeyi amaçlıyorsa, saygınlık ve etkisini artırması gerekmektedir -bunun yolu anaakım iktisatçıların dilini kullanmak olsa bile-; veya heterodoks iktisatçılar sahip oldukları saygınlık ve nüfuz temelinde kendi iletişim ağları, toplulukları ve dergileri çerçevesinde eleştirilerini sunmaya devam edeceklerdir. 


\section{Eskişehir Osmangazi Üniversitesi Iïß Dergisi}

\section{Kaynaklar}

Arestis, Phillip (1992). The Post-Keynesian Approach to Economics: An Alternative Analysis of Economic Theory and Policy. Cheltenham: Edward Elgar.

Arslan, M. Oğuz (2017). "Linking Agent-Based Computational Economics to Post Keynesian Economics”, Uluslararası Yönetim iktisat ve işletme Dergisi, C. 13, S. 1: 1-17.

Backhouse, Roger (2004). "A Suggestion for Clarifying the Study of Dissent in Economics", Journal of the History of Economic Thought, Vol. 26, No. 2: 261-271.

Black, John; Hashimzade, Nigar; Myles, Gareth (2013). A Dictionary of Economics. Oxford: Oxford University Press.

Caldwell, Bruce (2009). "Some Comments on Lawson's Reorienting Economics: Same Facts, Different Conclusions", Ontology and Economics: Tony Lawson and his Critics, (Ed. Edward Fullbrook), Routledge, London and New York: 13-19.

Colander, David (2000). "The Death of Neoclassical Economics", Journal of the History of Economic Thought, Vol. 22, No. 2: 127-143.

Colander, David (2007). "Pluralism and Heterodox Economics: Suggestions for an 'Inside the Mainstream' Heterodoxy”, Middlebury College Economics Discussion Paper, No: 07-24.

Colander, David (2010). "The Economics Profession, the Financial Crisis, and Method", Journal of Economic Methodology, Vol. 17, No. 4: 419-427.

Colander, David; Holt, Richard; Rosser, Barkley (2004). "The Changing face of Mainstream Economics", Review of Political Economy, Vol. 16, No. 4: 485-499.

Cronin, Bruce (2010). "The Diffusion of Heterodox Economics", American Journal of Economics and Sociology, Vol. 69, No. 5: 1475-1494.

Davidson, Paul (2005). "A Response to King's Argument for Pluralism", Post-Autistic Economics Review, Vol. 24.

Davis, John B. (2007). "The Turn in Economics and the Turn in Economic Methodology", Journal of Economic Methodology, Vol. 14, No. 3: 275-290.

Davis, John B. (2008). "The Turn in Recent Economics and Return of Orthodoxy", Cambridge Journal of Economics, Vol. 32, No. 3: 349-366.

Davis, John B. (2009). "The Nature of Heterodox Economics", Ontology and Economics: Tony Lawson and his Critics (Ed. Edward Fullbrook), Routledge, London and New York: 83-92.

Davis, John B. (2018). "Economics and Economic Methodology in a Core-Periphery Economic World", Working Paper, No. 2018-04, Marquette University, Wisconsin, USA.

Dequech, David (1999). "Expectations and Confidence under Uncertainty", Journal of Post Keynesian Economics, Vol. 21, No. 3: 415-430.

Dequech, David (2007). “Neoclassical, Mainstream, Orthodox and Heterodox Economics", Journal of Post Keynesian Economics, Vol. 30, No. 2: 279-302.

Dobusch, Leonhard; Kapeller, Jakop (2012). “Heterodox United vs. Mainstream City? Sketching a Framework for Interested Pluralism in Economics", Journal of Economic Issues, Vol. 46, No. 4: 1035-1057.

Dorfman, Joseph (1970). "Heterodox Economic Thinking and Public Policy”, Journal of Economic Issues, Vol. 4, No. 1: 122.

Dow, Shelia (2000). "Prospects for Progress in Heterodox Economics", Journal of the History of Economic Thought, Vol. 22, No. 2: 157-170.

Dow, Shelia (2004). "Structured Pluralism”, Journal of Economic Methodology, Vol. 11, No. 3: 275-290.

Dow, Shelia. (2008). "Plurality in Orthodox and Heterodox Economics", Journal of Philosophical Economics, Vol. 1, No. 2: 73-96.

Dugger, William (Ed.) (1989). Radical Institutionalism: Contemporary Voices, Westport, CT: Greenwood Press.

Eren, Ercan (2012). "Yerleşik İktisatta İçerik Kayması ve Paradigma Değişikliği”, Discussion Paper, No. 2012/51, Turkish Economic Association, Ankara.

Eren, Ercan; Uysal, Ezgi (2017). “iktisatta Yeni Heterodoks Gelişmeler”, Kırklareli Üniversitesi İktisadi ve İdari Bilimler Fakültesi Dergisi, C. 6, S. 2: 134-151. 
Fullbrook, Edward (Ed.) (2003). The Crisis in Economics: The Post-Autistic Economics Movement: The First 600 Days, , London and New York: Routledge.

Garnett, Robert (2006). "Paradigms and Pluralism in Heterodox Economics", Review of Political Economy, Vol. 18, No. 4: 521-546.

Gruchy, Allan (1947). Modern Economic Thought: The American Contribution, New York: Prentice-Hall Inc.

Hands, D. Wade. (2015). “Orthodox and Heterodox Economics in Recent Economic Methodology", Erasmus Journal for Philosophy and Economics, Vol. 8, No. 1: 61-81.

Heukelom, Floris (2014). "Mainstreaming Behavioral Economics”, Journal of Economic Methodology, Vol. 21, No. 1: $92-$ 95.

Holcombe, Randall (2008). "Pluralism versus Heterodoxy in Economics and the Social Sciences", The Journal of Philosophical Economics, Vol. 1, No. 2: 51-72.

Jackson, William A. (2018). "Strategic Pluralism and Monism in Heterodox Economics", Review of Radical Political Economics, Vol. 50, No. 2: 237-251.

Jo, Tae-Hee (2016). "The Social Provisioning Process and Heterodox Economics," MPRA Paper, No. 72384, University Library of Munich, Germany.

Kapeller, Jakop (2010a). "Citation Metrics: Serious Drawbacks, Perverse Incentives, and Strategic Options for Heterodox Economics", American Journal of Economics and Sociology, Vol. 69, No. 5: 1376-1408.

Kapeller, Jakop (2010b). "Some Critical Notes on Citation Metrics and Heterodox Economics", Review of Radical Political Economics, Vol. 42, No. 3: 330-337.

Lavoie, Marc (1992). Foundations of Post-Keynesian Economic Analysis, Cheltenham: Edward Elgar.

Lavoie, Marc (2006). "Do Heterodox Theories Have Anything in Common? A Post-Keynesian Point of View”, European Journal of Economics and Economic Policies: Intervention, Vol. 3, No. 1: 1-87.

Lavoie, Marc (2015). Post-Keynesian Economics: New Foundations, Cheltenham: Edward Elgar.

Lawson, Tony (1997). Economics and Reality, London and New York: Routledge.

Lawson, Tony (2006). "The Nature of Heterodox Economics", Cambridge Journal of Economics, Vol. 30, No. 4: 483-505.

Lee, Frederic (2009). A History of Heterodox Economics: Challenging the Mainstream in the Twentieth Century, London and New York: Routledge.

Lee, Frederic (2011). "The Pluralism Debate in Heterodox Economics", Review of Radical Political Economics, Vol. 43, No. 3: 540-551.

Lee, Frederic (2012). "Heterodox Economics and its Critics", Review of Political Economy, Vol. 24, No. 2: 337-351.

Mayer, Thomas (1998). “Boettke's Austrian Critique of Mainstream Economics: An Empiricist's Response”, A Journal of Politics and Society, Vol. 12, No. 1-2: 151-171.

Meador, D. Marshall (2009). "Comment on 'What is Heterodox Economics? Conversations with Historians of Economic Thought", Forum for Social Economics, Vol. 38: 71-73.

Mearman, Andrew (2007). "Teaching Heterodox Economic Concepts", The Handbook for Economics Lecturer, https://www.economicsnetwork.ac.uk/handbook/printable/heterodox.pdf, (Erişim: 03.04.2018).

Mearman, Andrew (2011). "Who Do Heterodox Economists Think They Are?”, The American Journal of Economics and Sociology, Vol. 70, No. 2: 480-510.

Mearman, Andrew (2012). "'Heterodox Economics' and the Problems of Classification”, Journal of Economic Methodology, Vol. 19, No. 4: 404-424.

Nelson, Julie (2003). "Confronting the Science/Value Split: Notes on Feminist Economics, Institutionalism, Pragmatism and Process Thought", Cambridge Journal of Economics, Vol. 27, No. 1: 49-64.

Rabin, Matthew (2002). "A Perspective on Psychology and Economics”, European Economic Review, Vol. 46, No. 4: 657685.

Rosser, Barkley (2011). "Post Keynesian Perspectives and Complex Ecologic-Economic Dynamics", Metroeconomica, Vol. 62, No. 1: 96-121.

Sawyer, Malcolm (1989). The Challenge of Radical Political Economy: An Introduction to Alternatives to Neo-classical Economics, Savage, MD: Barnes and Noble Books. 


\section{Eskişehir Osmangazi Üniversitesi IïBF Dergisi}

Sent, Esther-Mirjam (2004). "Behavioral Economics: How Psychology Made its (Limited) Way Back into Economics", History of Political Economy, Vol. 36, No. 4: 735-760.

Sherman, Howard (1987). Foundations of Radical Political Economy, Armonk, New York: ME Sharpe.

Slade-Caffarel, Yannick (2019). "The Nature of Heterodox Economics Revisited", Cambridge Journal of Economics, Vol. 43, No. 3: 527-539.

Wrenn, Mary (2007a). "Searching for Common Ground: Interactive Agency in Heterodox Economics", European Journal of Economics and Economic Policies: Intervention, Vol. 4, No. 2: 253-275.

Wrenn, Mary (2007b). "What is Heterodox Economics? Conversations with Historians of Economic Thought", Forum for Social Economics, Vol. 36, No. 2: 97-108. 